\title{
OCORRENCIA DE NIBILIA ANTILOCAPRA (STIMPSON) (CRUSTACEA, DECAPODA, MAJIDAE) NO NORDESTE DO BRASIL
}

PETRONNIO ALVES COELHO I ANN MARY PINHEIRO ABY FARAJ 2

\begin{abstract}
The majid spider crab Nibilia antilocapra (Stimpson), previously known from the West Atlantic coast, between the Lesser Antilles and North Carolina, is reported as found by fishermen on the Rio Grande do Norte coast, Brazil.

\section{INTRODUÇÃO}

O inventário da fauna marinha do Brasil é uma tarefa que ainda está longe de ser concluída. Uma prova deste fato está na descoberta de um caranguejo da família Majidae, cuja ocorrência ainda não tinha sido assinalada. Desta forma, a família Majidae, a mais rica do litoral brasileiro, com 66 espécies referidas por Coelho \& Ramos (1973), se vê enriquecida de mais um representante. Esta espécie recentemente coletada é constituída por caranguejos de porte relativamente avantajado e de configuração bizarra, causando admiração o fato de não terem sido percebidos anteriormente. $O$ espécimen foi identificado como Nibilia antilocapra (Stimpson), conhecida anteriormente do Atlântico Ocidental desde o Leste dos Estados Unidos até as Antilhas.
\end{abstract}

\section{HISTÓRICO DE NIBILIA ANTILOCAPRA}

O gênero Nibilia foi estabelecido por A. Milne Edwards (1898), descrevendo uma nova espécie $N$. erinacea, proveniente de Guadeloupe e de Maria Galante. Posteriormente, o mesmo autor $(1879,1891)$ acrescentou uma segunda espécie ao gênero, $N$. armata, proveniente igualmente do Mar das Antilhas. Stimpson (1871), no entanto, havia descrito duas espécies no gênero Pisa ( $P$. antilocapra e $P$. praelonga), coletadas ao largo dos arrecifes da Flórida. Os tipos destas duas espécies parecem ter sido perdidos, porém A. Milne Edwards \& Bouvier (1923) acreditaram tê-las reencontrado entre o material coletado pelo "Blake" na costa da Flórida (Golfo do México). A. Milne Edwards \& Bouvier não teceram qualquer comentário sobre a possibilidade de que seus espécimens, de 12,7 e de $20 \mathrm{~mm}$ de comprimento, pudessem pertencer ao gênero Nibilia, e muito menos à espécie $N$. erinacea, baseada em exemplar de $102 \mathrm{~mm}$ de comprimento. Coube a Rathbun (1925) mostrar que $N$. erinacea, $P$. praelonga e $P$. antilocapra eram baseadas em indivíduos pertencentes a uma mesma espécie, porém de tamanhos diferentes. A configuração e a ornamentação da carapaça apresentariam, desta forma, variações ligadas ao crescimento, que passaram despercebidas a A. Milne Edwards e a Bouvier, mas não a Ratḩbun, que teve à sua disposição exemplares de vários tamanhos. Williams (1965) concorda com a sinonímia proposta por Rathbun. O nome antilocapra foi escolhido por Rathbun por precedência de página na obra de Stimpson (1871).

Quanto a Nibilia erinacea, Rathbun (1894) constatou que diferia de $N$. spinosa em caracteres bastante importantes para justificar a criação de um novo gênero para abrigá-la, ao qual deu o nome de Holoplites; a espécie, portanto, é corretamente denominada $H$. armata.

1. Departamento de Oceanografia, Universidade Federal de Pernambuco. Bolsista do CNPq.

2. Departamento de Oceanografia e Limnologia, Universidade Federal do Rio Grande do Norte. 


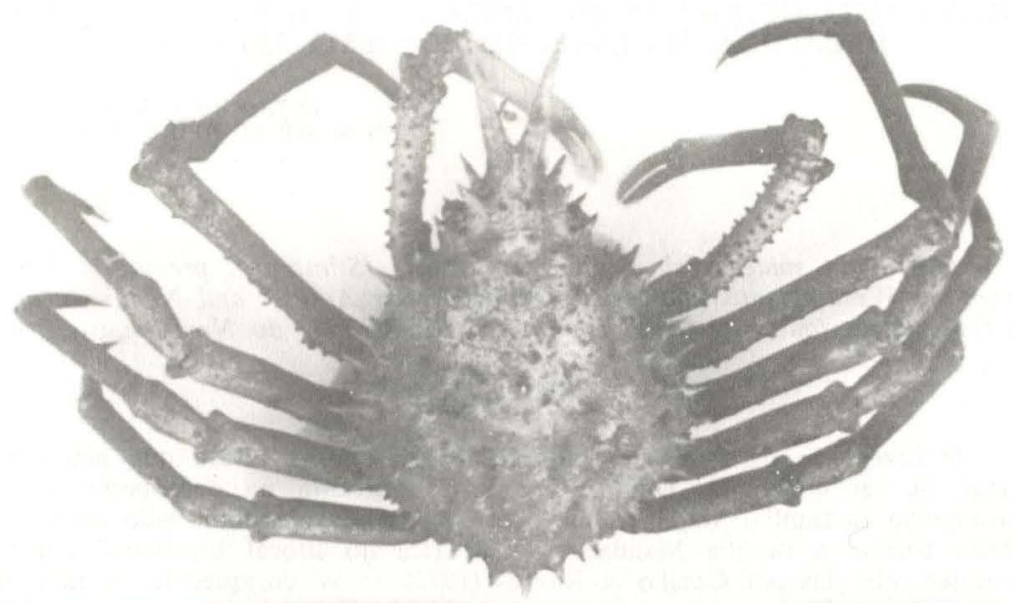

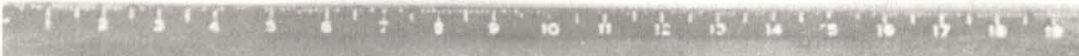

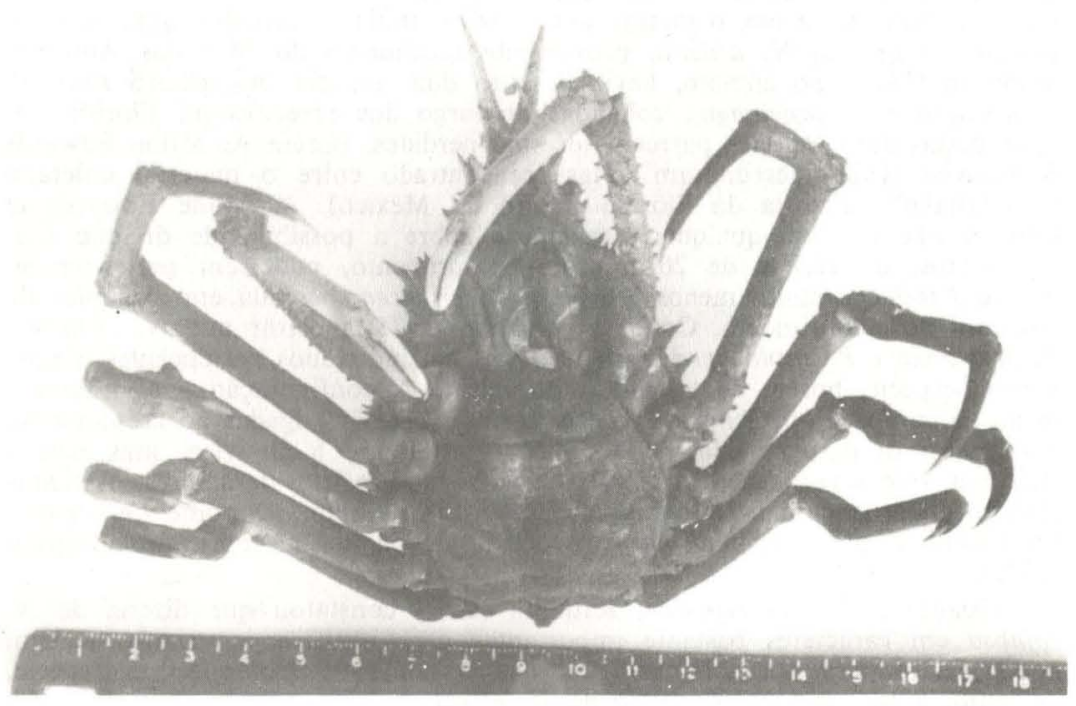

Fig. 1 - Nibilia antilocapra; a - vista dorsal; b - vista ventral. 
Nas classificações atuais, o gênero Nibilia é colocado na subfamília Pisinae (ver Garth, 1958).

Nibilia antilocapra (Stimpson)

(Fig. 1)

Herbstia. . Schramm, em Desbonne \& Schramm, 1867:17, pl. 7, fig. 23.

Pisa antilocapra Stimpson, 1871:110; A. Milne Edwards \& Bouvier, 1923:383, pl. 11, figs. 4 e 5, pl. 12, fig. 3; A. Milne Edwards, 1875:68.

Pisa praelonga Stimpson, 1871:111; A. Milne Edwards, 1875:69; A. Milne Edwards \& Bouvier, 1923:384, pl. 11, figs. 6 e 7, pl. 12, fig. 4.

Nibilia erinacea A. Milne Edwards, 1878:133, pl. 25.

Nibilia antilocapra; Rathbun, 1925:290, pl. 102, 103 e 239; Williams, 1965: 251; Powers, 1977:65.

Localidade típica: "Off Carysfort Reef", 52 e 60 braças; "of Alligator Reef", 118 braças.

Registros posteriores: Carolina do Norte (Rathbun, 1925), Flórida (Stimpson, 1871; A. M. Edwards \& Bouvier, 1923), Luisiânia (Rathbun, 1925), Antilhas (A. Milne Edwards, 1878; Rathbun, 1925).

Material: 1 fêmea, coletada em Pirangi do Norte, Município de Eduardo Gomes (Rio Grande do Norte), por pescadores profissionais a 3 de novembro de 1977. Os coletores informaram ter obtido o espécimen a 90 metros de profundidade. O espécimen se encontra depositado na Coleção Carcinológica do Departamento de Oceanografia e Limnologia, Natal, Rio Grande do Norte. O comprimento da carapaça é de $84 \mathrm{~mm}$ e a largura de $58 \mathrm{~mm}$.

\section{CONSIDERAÇÕES ECOLOGICAS E BIOGEOGRÃFICAS}

Os dados anteriormente existentes sobre $N$. antilocapra faziam acreditar que esta era uma espécie limitada ao Atlântico Ocidental, desde as Pequenas Antilhas até a Carolina do Norte. Dentro destes limites, seria encontrada sobre fundos rochosos, areno-cascalhosos, arenosos ou lamacentos, quase sempre de origem organogênica ou com fração organogênica importante. As coletas tinham sido realizadas entre 71 e 256 metros de profundidade, sendo a temperatura da água, junto ao fundo, de 13,6 a $23,9^{\circ} \mathrm{C}$.

Os dados de coleta do material examinado indicam que a área de ocorrência da espécie é muito mais vasta do que era suposto anteriormente, porém novas coletas poderão mostrar outros pontos de ocorrência ao longo do litoral brasileiro.

\section{REFERENCIAS}

Coelho, P. A. \& Ramos, M. A., 1973. A constituição e a distribuição da fauna de decápodos do litoral leste da América do Sul entre as latitudes de $5^{\circ} \mathrm{N}$ e $39^{\circ} \mathrm{S}$. Trabalhos Oceanográficos Univ. Fed. Pernambuco, Recife 13: 133-236.

Desbonne, I. \& Schramm, A., 1867. Crustacés de la Guadeloupe d'après un manuscrit du... I. Desbonne comparé avec les échantillons de Crustacés de sa collection et les dernières publications de MM. H. de Saussure ei de $W$. Stimpson. Première partie, brachyures. Imprimerie du Gouvernement, Basseterre, $60 \mathrm{pp}$.

Garth, J. S., 1958. Brachyura of the Pacific Coast of America. Oxyrhyncha. Allan Hancock Pacific Expeditions, Los Angeles 21: 1-6; 1-859; 1-55. Ilustrações 1-10, pls. A-Z, Z1-Z4.

Milne Edwards, A., 1873-1881. Études sur les crustacés Podophthalmaires de la région mexicaine. Mission scientifique du Méxique. Recherches zoologiques pour servir à l'histoire de la faune de l'Amérique Centrale et du Méxique 1(5): 45-368. 
Milne Edwards, A. \& Bouvier, E. L., 1923. Reports on the results of dredging under the supervision of Alexander Agassiz, in the Gulf of Mexico (1877-78), in the Caribbean Sea (1878-79) and along the Atlantic Coast of the United States (1880) by the U. S. Coast Survey "Blake". Les porcellanides et les Brachyures. Mem. Mus. comp. Zool., Cambridge 47(4): 283-305.

Powers, L. W., 1977. A catalogue and bibliography to the crabs (Brachyura) of the Gulf of Mexico. Contr. Sci., Port Aransas Marine Laboratory 20(Suppl): 1-190.

Rathbun, M. J., 1893. Notes on the crabs of the family Inachidae in the United States National Museum. Proc. U. S. natn. Mus, Washington, D. C. 17: 43-75.

Rathbun, M. J., 1925. The spider crabs of America. Bull. U. S. natn. Mus, Washington, D. C. 129: 1-613.

Stimpson, W., 1871. Preliminary report on the Crustacea dredged in the Gulf Stream in the Straits of Florida. Part I. Brachyura. Bull. Mus. comp. Zool. 2: $109-160$.

Williams, A. B., 1965. Marine decapod crustaceans of the Carolinas. Fish. Bull., Washington, D. C. 65(1): 1-298. 